\title{
Relevance of Walking and Informal Activities in Urban Space: A Case of Dar es Salaam City, Tanzania
}

\author{
Fortunatus Bahendwa ${ }^{1}$ \\ ${ }^{1}$ School of Architecture, Construction Economics and Management, Ardhi University, Tanzania \\ Correspondence: Fortunatus Bahendwa, School of Architecture, Construction Economics and Management, \\ Ardhi University, Tanzania. E-mail: fortub72@gmail.com
}

Received: April 25, 2017

doi:10.5539/jsd.v10n4p43
Accepted: May 9, $2017 \quad$ Online Published: July 30, 2017

URL: https://doi.org/10.5539/jsd.v10n4p43

\begin{abstract}
The design discourse mostly in developing world cities tends to commit walking as the concern for transportation purpose. This notion tends to dismiss walking as an extended conception of urban space and take it for granted which allow elements of informal walking fields to emerge. This orients walking in the lines of a mere 'street sidewalk' rather than an important element in enhancing urban space in terms of environmental quality, access and use of urban space and everyday life realities. The empirical study in Dar es Salaam show that the gap in walking provision seem to be filled by the informal actors in urban space struggling to create the informal walking spheres in which trading, vending, meeting and recreating take place. Such observations draw a lesson that such informal developed urban activities along the streets and the urban space have not been disassociated from walking. The paper recognizes the essence of such integration of walking with other activities in urban space. It is thus concluded that urban design discourse have to conceive walking, including its contextual elements, as integral component in the field of urban public space that connect with other urban functions rather than isolate it from them.
\end{abstract}

Keywords: city, informal activities, mobility, urban space, walking

\section{Walking as Significant Means of Mobility in Cities of Developing World}

It is quite normal for cities facing mobility challenges to commit walking entirely to mobility purposes. The connection of walking to urban space as a tool for access, use, interaction and experience of the urban space is not yet featured adequately. In such cities, the dominant factors such as less compliance to professional city designs, relative organic city development structure, inadequate infrastructure provision and the dominance of low income group as the majority of city population lead to cities in developing world to depend heavily on walking as the basic mobility option. The dependency on walking in most cities of Africa indicate that walking accounts for 81 percent of all trips in Dakar, Senegal; 70 percent in Addis Ababa, Ethiopia; 63 percent in Harare, Zimbabwe; 60 percent in Bamako, Mali; 47 percent in Nairobi, Kenya; 45 percent in Dar es Salaam, Tanzania and 42 percent in Ouagadougou, Burkina Faso (Cox, 2012; Pendakur, 2005: 9). On the other side, Mkalawa (2014) notes that Dar es Salaam city residents use public transport Daladala(A Swahili slang for a small minibus and medium-sized city buses. The name is old slang for 5 Shillings, the standard fare when the service was first introduced) and walking as the major means of transport where the mobility share account for 62 percent and 17 percent respectively. Such enormous walking potentials provide opportunity for urban professionals in developing world cities for creation of public urban spaces attractive for walking and other associated public functions.

Further, walking contribute in supporting public transport facilities, improve the overall liveability of cities, provide accessibility within built areas and offer an alternative means of movement away from private vehicles for short-distance trips. Despite their strong dependence on walking, cities in developing world are rarely strategically planned to support and exploit the benefits of walking. Furthermore, the inadequate social services provision and the city orientation towards sprawling development is rarely walking friendly and encourages the use of motorised transport (Anciaes, Nascimento, \& Silva, 2015; Kiunsi, 2013; Cox, 2012; Banyikwa, 2007). This situation shifts the attention of planners who tend to concentrate on solving car mobility issues at the expense of ignoring other modes of transport including walking (Leather, Fabian, Gota, \& Mejia, 2011). The growth in road traffic demand is accommodated in new road infrastructure where priority is given to motorised 
modes of transport.This indicates that the potentials in walking primarily as significant contributor to mobility and its extended roles in urban space are not exploited adequately in cities' development policies, city planning and design disciplines. This raise questions on to what extent the walking approach have been conceived among professionals in city design and planning disciplines in developing world.

\section{Extensive Approaches of Walking in Urban Context}

Walking is viewed as form of movement and everyday life activity in the city and thus a 'social activity' (Shortell, 2016; Mehta, 2008; Wundelich, 2008; Lekule, 2004). Apart from being connected with everyday life activity, the design input can contribute to enhance the walking and integrate it with other activities. Designers are also interested in the sensory effects and environment as a social setting that provides sensory stimulation but also supports the expectations of its users including desirable environment for walking (Makki, Surat, Che-Ani, Farkisch, \& Mokhtarian, 2012; Mehta, 2008). The concept of 'walkability' has also been introduced to address the important measure of environment for walking where comprehensive studies and city plans has been done to improve walkability. Transport for London (2004) defines walkability as "the extent to which walking is readily available to the consumer as a safe, connected, accessible and pleasant activity." For New Zealand, it is defined as the extent to which the built environment is walking-friendly (Leather et al, 2011). Walkability measurement may differ based on the definitions and types of measurements used to measure both walking and walkability attributes such as indicator selection, spatial scale, and trip purpose (Tribby, Miller, Brown, Werner, \& Smith, 2016).

The aspect of walking as a means of a person interacting with the environment is highly interesting for urban design and at the same time making an impact to the image of the city. Jacobs (1961) claims that, streets and their sidewalks, as the main public spaces, are the most vital organs of the city since it is the street which comes to mind when one thinks of the city. In that case, if a city's streets look interesting, the city looks interesting; if they (streets) look dull, the city looks dull. Such Jacob's concern is not only inclined to street quality but also its effect to environment for walking. Wundelich (2008) associates walking as an elemental way of perceiving urban places. He notes that when one experiences, he learns about places and develops feelings and thoughts for them. He further emphasises that 'to walk is to experience', and 'to experience is to learn'; which means acting on the given and creating out of the given. The given cannot be known by itself. What can be known is a reality that is a construct of experience, 'a creation of feeling and thought'. Thus, Wundelich (2008) notes that walking is an active mode of perceiving the urban environment assisted by all the senses.

'Walking' is also associated with sustainable city development especially for its environmental, economical and social benefits. On environmental perspective, walking may replace substantial car trips, contribute in reduction of car congestion, reduce emission of greenhouse gases, enhance health, stimulate extensive use of urban space and other benefits with broader positive environmental impact to individuals and the community at large. Socially and economically, walking may reduce transportation cost, increase the use of public space, increase retail sale and the like. Such benefits have to make walking regain its importance to urban and city planners who are challenged to create new pedestrian places in car-oriented cities. Therefore, walkable environments have to be integrated in urban planning, not solely as urban architectural and design exponents, but also as interaction and meeting platform, as determinants of human mobility in a car-dependent society (Blaga, 2013; Mrema, 2013: 210; WHO, 2011).

Health analysts view walking as an active activity which can improve the health of the walker (Reyer et al, 2014; Planning Institute Australia, 2003). Such concern has been raised by the growing inactive urban community, especially in the developed world, which are heavily dependent on car transportation. Since the population physical activity volume is important in this case, the walkability indices have to be attained on daily or weekly basis to ensure a health life of the population is achieved. The proper active life gained through the developed habit of walking to a minimum specified index may help the respective population to reduce non-communicable diseases such as obesity, coronary heart diseases and type-2 diabetes (Reyer et al, 2014).

Some analysts connect walking with crime and safety (Cibukcu, 2013; Jacobs, 1961). They recognise walking as a facilitator to safety which lead to sustainability of a place. They note that the design which does not integrate the neighbourhood dwellings appropriately with the sidewalks and fail to create intermediate destinations will discourage the need for walking and render the streets empty creating potential environment for crime. Few and isolated walkers on empty streets are likely to be mugged and thus deny the street with inclusive appropriation and control. But when streets are walking friendly with environment encouraging a reasonable walking population, they become safe and fairly crime-free. Jacobs (1961) note that: users on the sidewalk must be there fairly continuously, both to add to the number of effective eyes on the street and to induce the people in the 
buildings along the street to watch the sidewalks in sufficient number. The Jacob's position to ensure safety integrate walking and all other activities for collective appropriation and control of neighbourhood space by all adjoining home owners, business owners and other street users.

Other analysts look at walking as a means to increase retail sale. Walking as engaging, interacting and momentarily taking part in activities along the path especially the trading enhance the retail sale and support local economy by encouraging residents to shop in the nearby areas (Blaga, 2013). Walking make the retail business accessible and form a part of the business. The walking and retail business may form a close relation as they tend to enhance and build on each other. Street vendors, whether walking or stationary, also become part of walking community for the sake of tapping customer among walkers for their business.

Walking is also associated with the concept of 'Shared Space' which does not focus on limiting car traffic and its speeds, but on voluntary behavioural change of all road users, supported by appropriate design and layout of public space with the view to improve safety, mobility and accessibility. The 'shared space' concept has been developed from the increasing contradiction of strictly separation of different modes of movement such as walking, biking and driving. The separation of such space includes extensive use of pedestrian barriers, traffic restriction elements and numerous traffic signs. The installed facilities for traffic restriction contribute to cause stress to traffic users and disrupt the image of public space and the city as a whole. And most importantly, despite strict separation of movement spaces in order to improve safety of users, very little have been recorded on reduction of traffic accidents. It is considered that proper design of shared traffic movements where the traffic rules such as traffic signs and typical traffic engineering elements are eliminated may improve the traffic behaviour of pedestrians and drivers to negotiate in shared space by utilising the informally developed social rules. The concept is built on the findings that when car drivers are more fully aware of and integrated into the pedestrian realm, both pedestrians and drivers are safer (Hamilton-Baillie, 2008; Methorst, Gerlach, Boenke \& Leven, 2007).

The perspective on walking as active element of urbanity is numerous as reflected in the discussion above. The walking approach to be adopted in city design should take the extensive dimensions of walking other than a mere means of transport. All the design attributes aimed at promoting walkability in built environment and enhancing the sustainable access and use of urban space have to reflect the concept of walking as complex and heterogeneous activity.

\section{Conceptual Framework}

Walking in city is linked to community's nature, norms and values of everyday life, environmental quality of urban spaces, accessibility of places and the extent to which spaces are usable. Whenever the city design does not offer such characters favourably, the negotiated informal elements managed by the community's customs and local norms emerge to fill the gap to capture the missed features in formal design.

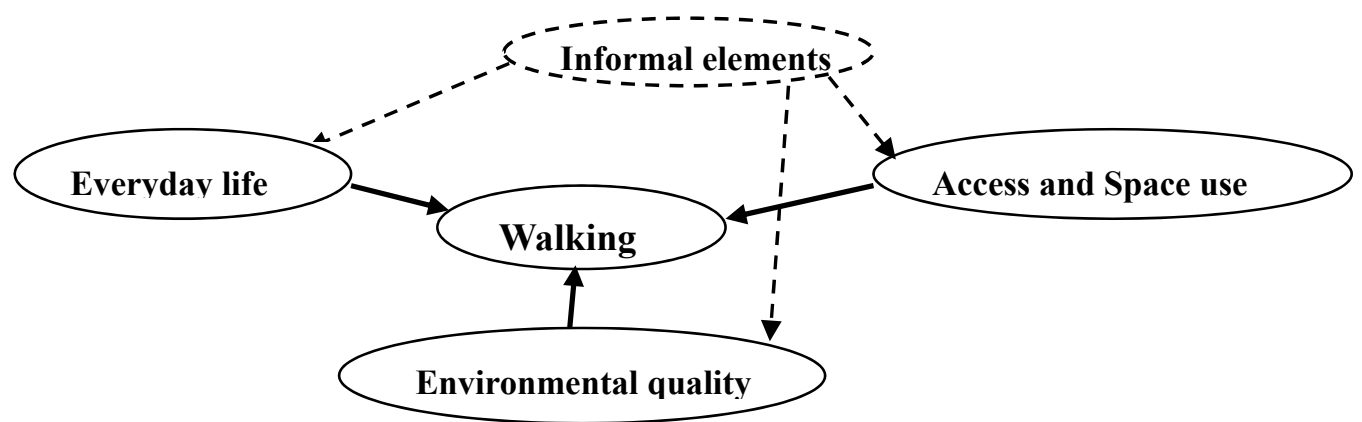

Figure 1. The relationship of walking with everyday life, environmental quality, access and use of urban space and the involvement of informal elements to supplement the lack in design

\subsection{Walking as Everyday Activity}

The element of walking as everyday activity elevate its conception beyond mobility aspects where it is no longer a stable and homogeneous activity of a person walking from point ' $A$ ' to ' $B$ '. The walking activity is more regarded as multiple and highly mutable action. This identify two main direction of view, that is, walking as means of solving another problems, such as walking as a means of transport, and walking as a self sufficient part of the complex embodied practice of human everyday life (Kärrholm et al, 2014). Along that view, Gehl (2010) notes that man was created to walk and most life's events develop when we walk among other people. He adds 
that life in all its diversity unfolds before us when we are on foot. A multitude of valuable social and recreational opportunities naturally emerge when you reinforce life on foot. Gehl observes walking as human natural phenomenon which is performed as part and result of human everyday life. Shortell (2016), assessing actions which necessitate presence of people in streets, views the social actors such as local politicians, worker, protesters, busy commuters, tourists and many more to occupy the city streets as an essential part of their quotidian routine. This everyday mobility on street and public spaces of neighbourhood is such an ubiquitous part of urban life and culture that the design discourse has to recognise and appreciate.

\subsection{Walking as Means of Access and Space Use}

Walking is viewed as practical and social activity, an unquestioned form of movement through the city, an ordinary activity in our everyday life in the city, but it is also increasingly associated with a way of living in a city, a way of extending the social realm beyond, and between, home and work (Shortell, 2016; Mehta, 2008; Wundelich, 2008; Lekule, 2004). In city design discourse, conducive environment for walking is relatively associated with design especially that involving mixed land use, higher density, presence of walking destinations and availability of convenient walking facilities (Kärrholm et al, 2014). Some studies claim the built environment which supports walking should have "3-D"s characteristics, which are: Density, Diversity and Design (Kärrholm et al, 2014; Reyer et al, 2014; Blaga, 2013; Mehta, 2008). With 'Density', the city community is provided in larger population on smaller area to be as close as possible to shorten the distance making the walking feasible. With 'Diversity', the most demanded services such as residences, shopping, recreation, public transport stand, schools, worship places and others are provided within the vicinity to support the walking idea. With 'Design', the access to various services is made convenient with walking facilities provided appropriately and clear from or supported with other modes of transport.

\subsection{Environmental Quality as Prerequisite Factor to Walking}

Designers mostly emphasise the sensory effects of environment as a social setting that provides users' spatial satisfaction but also support desirable environment for walking (Makki et al, 2012; Mehta, 2008). Walkability, as put forward earlier, may constitute different factors used to measure both walking and walkability attributes such as indicator selection, spatial scale, and trip purpose (Tribby et al, 2016). However, whatever criteria used to determine walkability scale, it has to reflect on the measurable condition by which built environment support or inhibit walking. Further, according to Certeau (1984), walking provision restrained by the predesigned modern conditions may not satisfy the walkers' aspirations. In this way, the walkers may develop creative resistance to repressive modern design to make the city useful, meaningful and expressive to them. This Certeau's notion explains that despite the fact that city designs may influence walking characteristics, walking behaviour in cities will reasonably find its independence and act with more unpredictable measures. This Certeau's contribution reveals the walker's search for quality walking environment to the extent of struggling to bridge the design failure or restrictions. This emphasises the relevance of appropriate design for the overall enhanced city spatial quality where, among other numerous city functions, walking is suitably accommodated.

Some analysts see walking as complex and manifold activity where different kinds of walking affect the nature of walking rhythm and the body interaction with the environment. Wundelich (2008) tend to distinguish walking as purposive, discursive and conceptual. Purposive walking is a kind of necessary walking or utilitarian phenomenon. Discursive walking is the type of walking or roaming where destination is not as important as the journey itself. The conceptual walking refers to a way of obtaining new knowledge of the place through walking. In this way, distinction can be made in terms of how an environment can afford various effects to different types of walking, for instance, environment supporting utilitarian walking may not necessarily support leisure walking and so on. It is also considered now that most concept of design, including the design for walking, has to take into consideration the paradigmatic change such as the ongoing change from modernistic zoning which mostly encouraged separation of function to design for co-existing activities and patterns of shared space which encourage higher densities and mixed land use (Hamilton-Baillie, 2008). Further shift are the change from socially homogenic communities to spaces of hyper-diversity which encourage heterogeneous community engagements. This would not only integrate variety of social classes in walking realm but also develop relatively equal opportunity for all classes to access urban public space.

\subsection{Informal Aspects}

Informal aspects associated with walking are the unregulated and unofficial local elements which are not preconceived as part of intervention to environment by formal design. In this respect, environmental quality, access and space use tend to reflect the real local socio-economic condition, norms, values and the pragmatic response to everyday life requirements of the urban community. Such process of negotiated practices in real 
urban space result to environment which may not necessarily lead to pleasant use of urban space in which walking form a part. However, the continued informal use of urban space may keep on evolving to a relatively pleasant use of urban space which eventually may support favourable use of urban space where walking is part.

Walking, with its mobility aspect, is interactive and social activity as it facilitates access to spaces and activities. This connects the act of walking, the nature of space and the space users' activities which result into creation of interactive spatial sphere unified by walking. It is from this notion that where walking requirements are not satisfied by formal design, the elements of informal practices emerge to fill the gap (Certeau, 1984). It is through walking that urban space are experienced, accessed and used while interactions and temporal negotiations of space occur.

\section{Methodology}

The key understanding of walking in the city that extends beyond mobility conception has been sought from literature review. The empirical information is primarily gathered through meticulous observations and interviews with the walking people and petty traders in selected walking streets. A total of 240 walking respondents and 100 petty traders located on two streets are interviewed where 120 pedestrians and 50 petty traders are involved in each street. The field surveys are done to collect data on the walking convenience; comfort; safety and security; space experience; visual impact and the effect of informal activities to walking. The streets involved in the study belong in two different areas in Dar es Salaam city where one area is reasonably formal planned area and the other less formal planned area. The first area is along Azikiwe street turning into Samora Avenue in the city centre where car carriage way and pedestrian walkways are relatively provided. The second area is along Shekilango road in Sinza area where only the car carriage ways are provided and pedestrian walkways are rarely provided. Both routes are chosen due to their importance as commercial corridors, major routes for public transport and their character of being fed with walkers and other modes of mobility from branches of streets connecting to them. Such routes are mainly taken as a continuous space in which walking, riding, driving, trading, vending and social interaction take place and not necessarily as special routes for walking only. The selected routes are sample space where comparatively richer relationship of walking and other urban activities are realised. The observations concentrate on the walking activity, the activities associated with walking, condition of walking space and the conditions supporting or inhibiting walking within the space. The data collection methods include interviews, observations, map analysis and focused participatory walking sessions along the routes. Perspectives from literature search, the author's profession as architect and his experience as Dar es Salaam dweller were important factors guiding the interviews, observations and walking sessions. The analysis involve comparing and aggregating data from observations and interviews with the view to develop explanation on the relevance of walking to environmental quality, access and use of space, habit of everyday life activity and the effect of informal activities to walking environment. The results are used to interpret the observed outcome into wider theoretical understanding of walking in city aiming to expand the professional conception of walking viewed in the mirror of localised urban context.

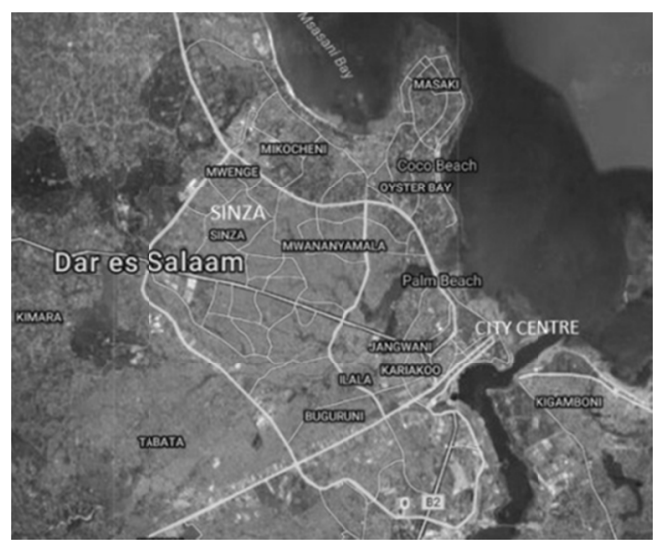

Fig. 2. Dar es Salaam City as it stretches radially from the city centre towards outer city areas.

Source: Google Map

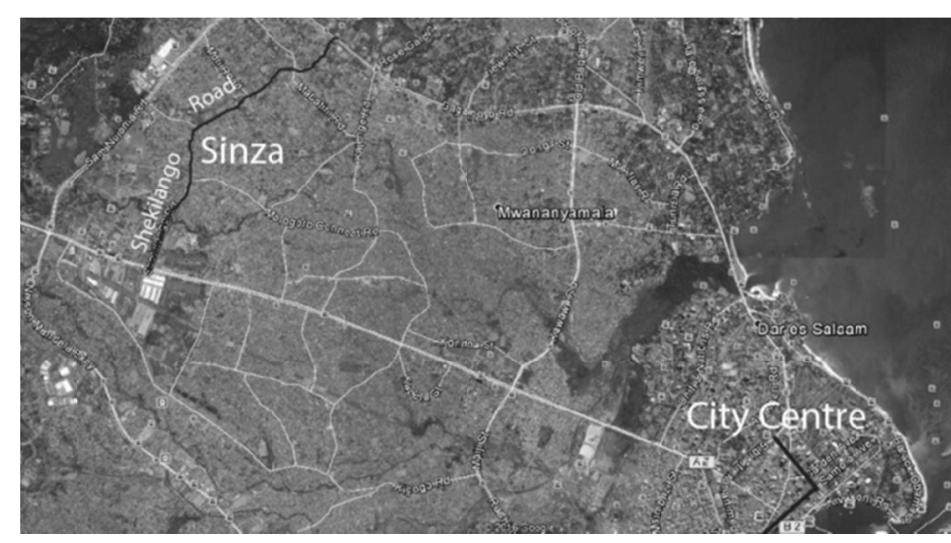

Fig. 3. The location of city centre and Sinza area. Walking path in city centre are clearly provided while they are not provided in Sinza

Source: Google Map 

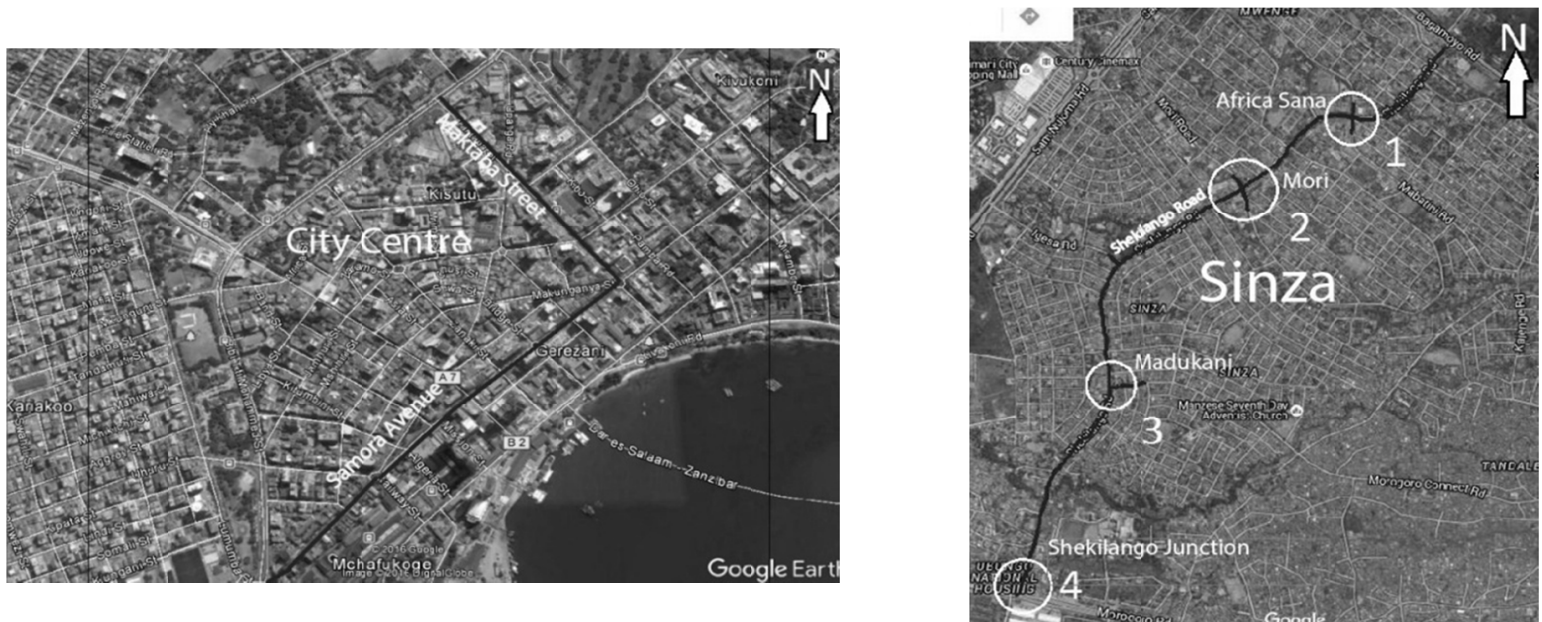

Fig. 4. (Left) Maktaba Street \& Samora Avenue in the City Centre. (Right side) Shekilango Road in Sinza The points 1-4 along Shekilango road in Sinza are the emerging centres which also result into 'walking hubs'. Both streets are explored through observations and interviews on their walking condition and the associated public spaces and activities.

Source: Google Map and authors construction

\section{Result and Discussion}

It is observed that paved sidewalks for pedestrians are rarely provided along Shekilango road in Sinza. The emphasis on provision of mobility facility seems to be entirely inclined to provision of vehicular road only. In this situation, the regulatory traffic signs, symbols and guides have no place whatsoever. Pedestrians usually walk on the road side along the informally developed earth foot paths. In some cases, the spaces adjacent to road side are controlled by the adjoining land developers or taken over by the petty traders which push the pedestrians to share momentarily the use of road carriage way with the moving cars (See Figure 5). The resulting walking continuity is fragmented where pedestrians negotiate their way through competing with obstacles such as land developers, petty traders, parking use and the other occupier on the 'assumed' walking space. The practice indicates that ample space for 'right of way' on the roadside which is mostly used by pedestrians is not guaranteed. The walking condition along Shekilango road, as the general condition of walking in most outer city streets, is rarely convenient or safe.
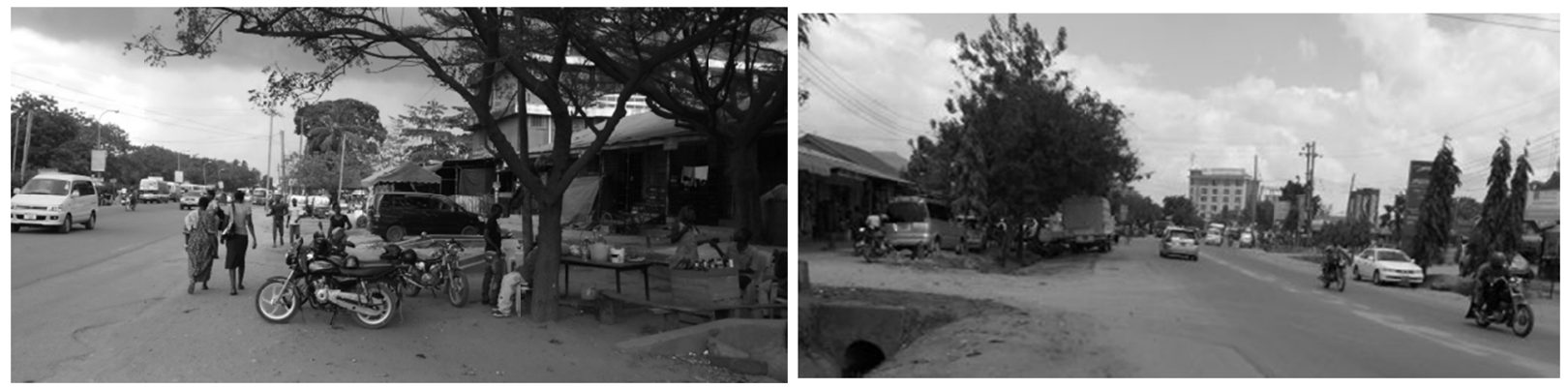

Fig. 5. Motorcycle stand, petty trading, occupation by land developer and car parking are some of activities which have taken over the space for pedestrians to walk through. Pedestrians are, thus, sometimes forced to find their way through or pushed to walk by the shoulders of the road in some cases

On Shekilango road, cars can park at any point along the informally established walking space since neither specific pedestrian walkways nor specific parking areas are provided. Thus such functions, and others, share the space along the roadside (see Figure 5). The developing of some formal and informal shops, commercial activities, petty trading, recreation and social activities along the road contribute significantly to form and 
maintain a fairly continuity of walking connecting with various activities along the roadside. Traders seem to view walking as important activity to them since out of 50 petty traders interviewed along Shekilango road in Sinza, 80 percent of them acknowledged to depend much on pedestrians as their customers. Furthermore, 66 percent of pedestrians claim to use the petty traders' services including buying goods from them. This indicates the relationship between the street petty trading and the walking activities. In cementing such relationship, 79 percent out of 50 petty traders interviewed in Sinza pointed out that they prefer to locate themselves in areas with concentration of pedestrians. Additionally, about 75 percent of them indicated that their business was doing fairly well but they had to move from one location to the other if necessary to follow better concentration of pedestrians (see Table 1 and 2). One petty trading respondent in Sinza noted that:

"Generally, the business is currently fairly tough such that sticking permanently to one location may be tricky. Thus, whenever I feel the customers have shrunk, I move to another location with reasonable concentration of customers (pedestrians). You know, we are the one who look for customers, and not customers looking for us".
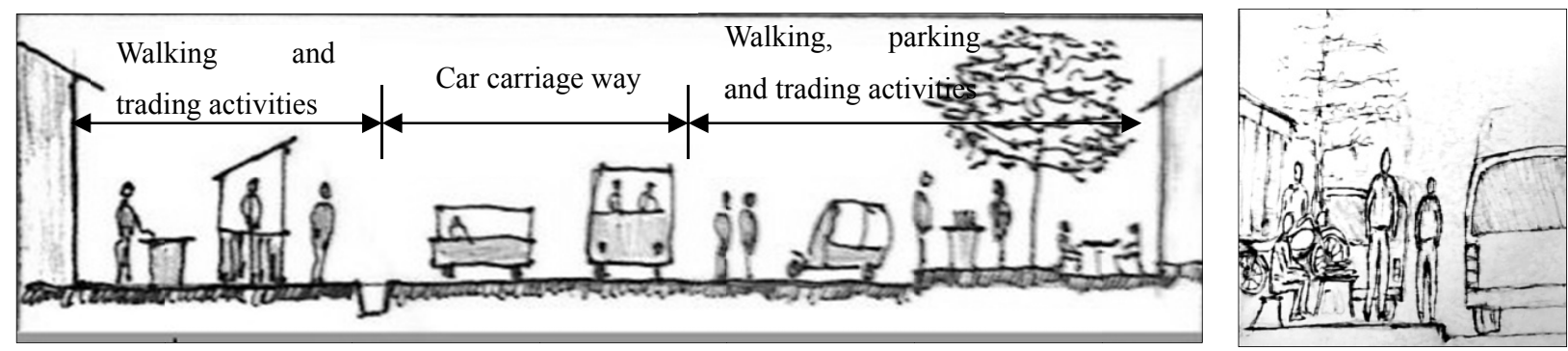

Fig. 6. Along Shekilango road: LEFT, walking is engaged with informal activities such as trading, parking and socialising. Interviews show that pedestrians are reliable customers to the petty traders which create the bond of the walking and informal trading. RIGHT, the image indicating coexistence and interaction of walking and other activities

Table 1. The comparative summary on trend of interview responses from pedestrians on important parameters of walking and the associated activities in Sinza and City Centre

\begin{abstract}
If organised, parking \& petty trading are acceptable
Difficulty in crossing road

Pedestrians using petty traders' services

Petty traders affect walking

Uncomfortable with walking environment

Low walking safety

Hot humid weather affect walking desire

Walking to save cost

Preference of walking for shorter distance

Purposive walking
\end{abstract}
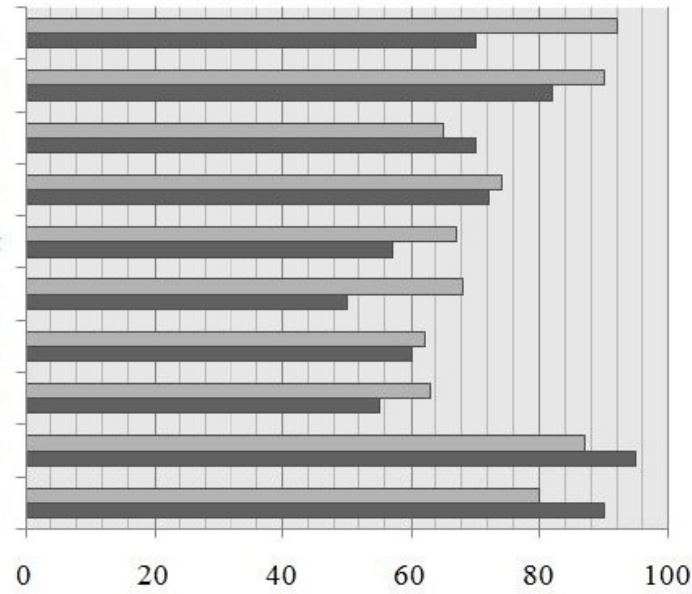

$\square \operatorname{Sinza} \%$

- City centre $\%$

People walk to achieve a certain course whether purposive, discursive or conceptual. About 80 percent of 120 interviewed pedestrians in Sinza are walking purposively such as going to work, shop or bus stop. 50 percent of interviewed pedestrian are using a given route due to its convenience towards the destination. It is observed that walking people towards and along Shekilango road are destined towards key junction points or urban centres (see Figure 4) where various services and most bus stops for daladala are located. From 120 walking people interviewed, about 63 percent, claim to walk to save cost. However, they indicated that they would use public transport for longer distances. Whether the environment for walking along Shekilango road is attractive, 25 percent of pedestrian appear to enjoy the street condition, activities, buildings and the scenery. However, 67 
percent did not enjoy walking experience due to lack of paving, awkward walking route, intrusion of other function such as parking, biking, riding and others. Further, 72 percent of interviewed pedestrian indicate that petty traders interfere with walking although 80 percent of petty traders claimed that pedestrians were their reliable customers (see Table 1 and 2).
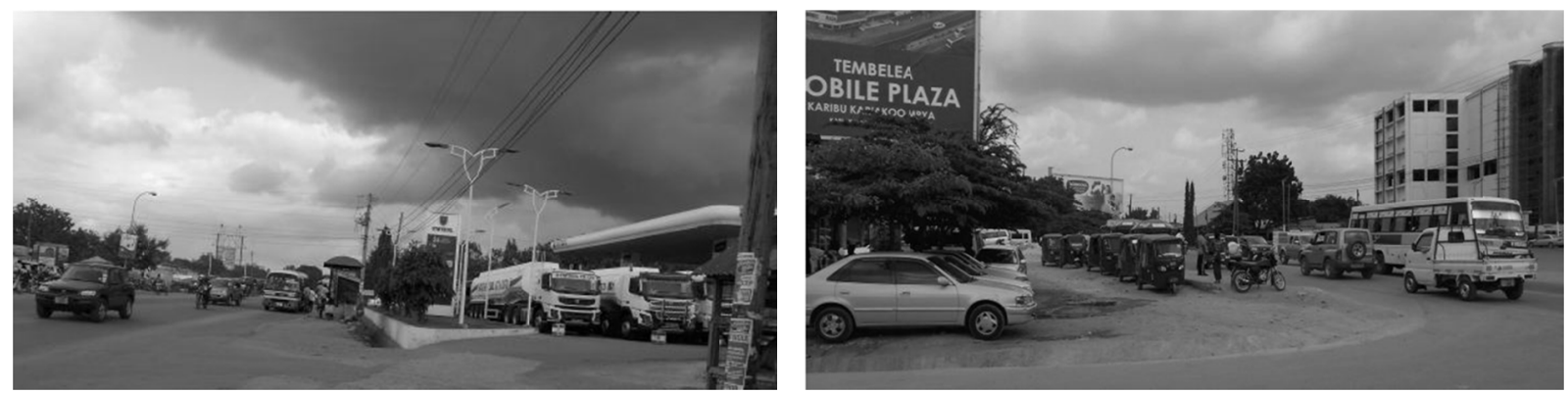

Fig. 7. Africa Sana and Mori centres which attract concentration of services such as bus stops, taxi stand, tricycle and motorcycle stand, series of shops, groceries, fuel stations, restaurants, bars, markets and others and thus become the key walking destinations or transit points

There are points along Shekilango road which are emerging as urban centres and thus becoming into 'walking hubs' and 'urban nodes'. These centres are mainly located at road junctions, such as Africa Sana, Mori and Madukani areas where movements from different directions meet (see Figure 4 and Figure 7). This character have made them to attract concentration of services such as bus stops, series of shops, groceries, fuel stations, restaurants, bars, markets and others and thus develop into walking destination and transit points. It is from this points where most walking people are recorded.

Table 2: The comparative summary on trend of interview responses from petty traders on important parameters of vending activities, walking and the associated activities in Sinza and City Centre

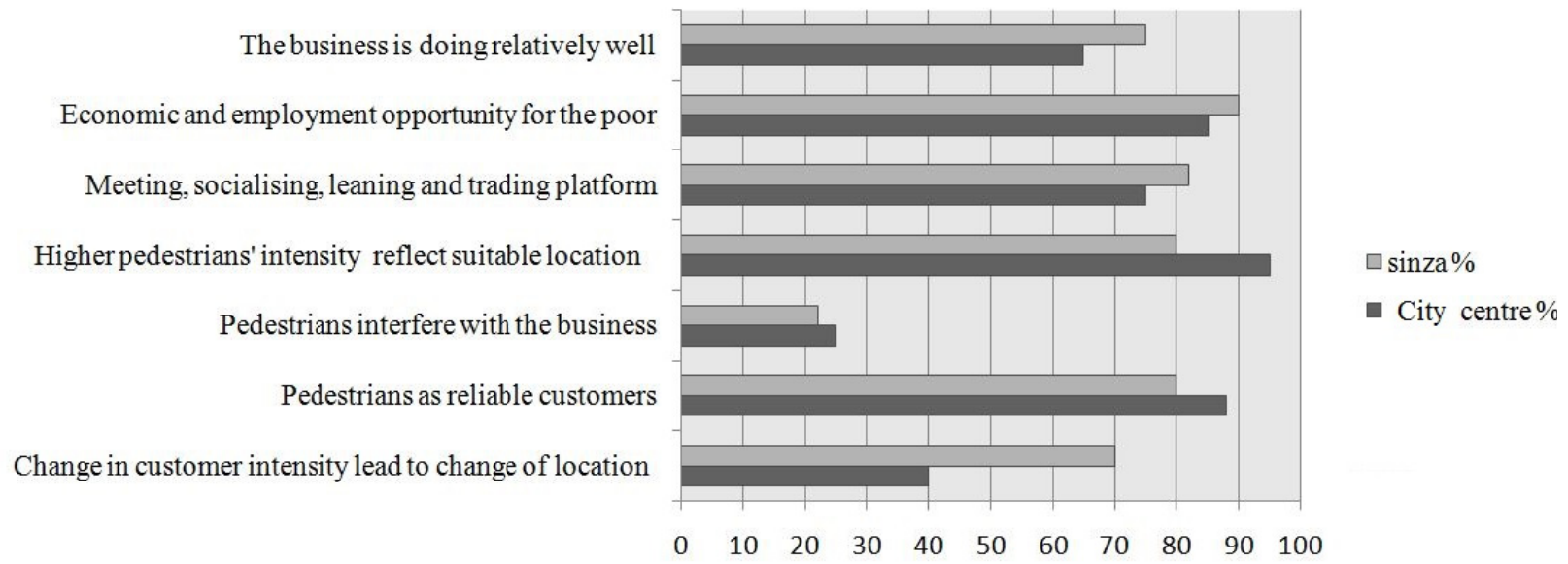

The pedestrian walkways in the city centre are relatively defined, reasonably maintained, fairly paved, open or enclosed space and separated from car carriageway (see Figure 8). This result to varied quality of walking surfaces with the building and the associated commercial services provided. From this point of view, 57 percent of interviewed pedestrian indicate that they do not enjoy their walking experience due to inconsistent quality of walking surface and the intrusion of other activities such as car parking, riding, bilking and vendors along the walking route. 72 percent of interviewed pedestrian were not happy with the way vendors grab part of walking space as they squeeze it. However, they mostly (70 percent) suggested that informal activities could be organised properly along the street since they are useful to pedestrians. In this way 70 percent of interviewed pedestrians show that they usually use the petty traders' services since they typically get better business deals, save time and 
energy they would need to go to formal shopping (see Table 1 and 2).
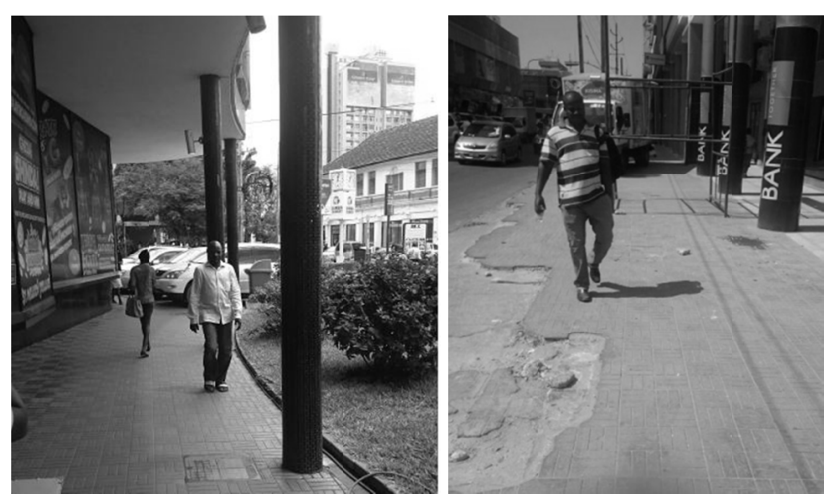

Fig. 8. The quality of walkway surfaces contributed to unfavourable experience of pedestrian along the route

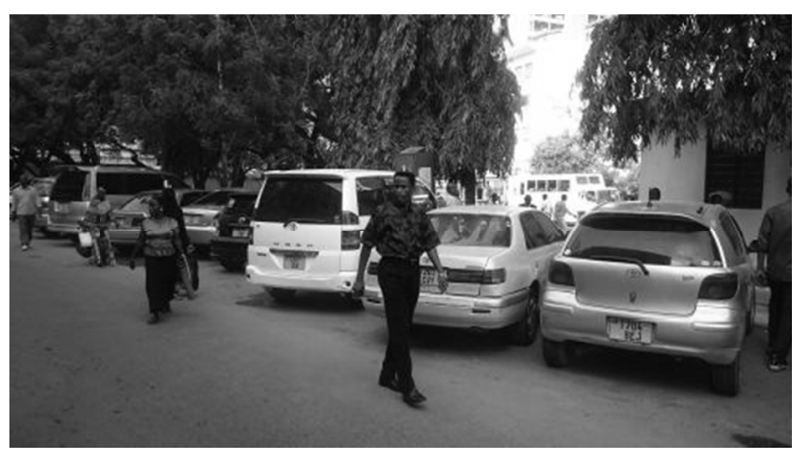

Fig. 9. The demand for car parking space is increasingly claiming some share of the walking space

The increased use of private cars indicates the increased demand for parking which intrude some share of the walking space (see Figure 9). This situation affects the nature and efficiency of walking flow. It is noted that, in the city centre, people are walking purposively such that they have to adopt the walking condition encountered. It is noted that about 90 percent of 120 interviewed pedestrians had an important place to go such as going to school, work, shop, bank, office, bus stop, an appointment and the like (see Table 1).

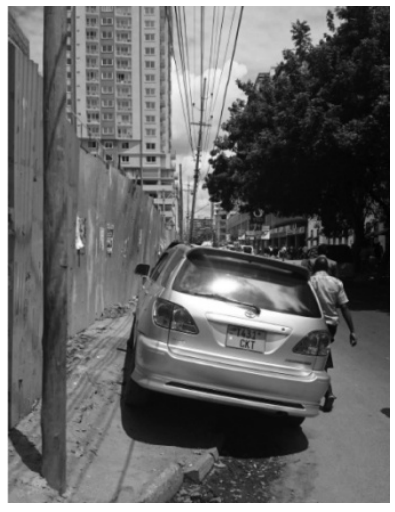

Fig. 10. The walkway is blocked with sheet fencing to shield the building under construction. The unspecified parking interrupt with walking flow

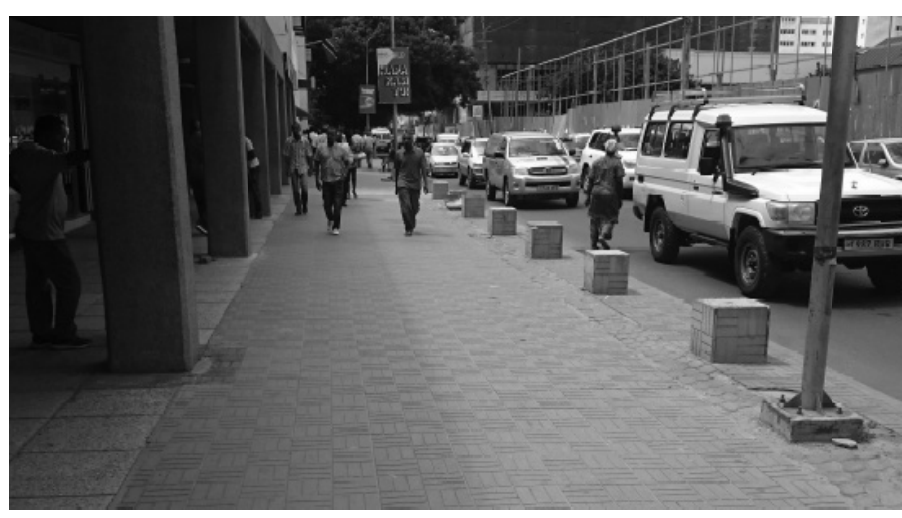

Fig. 11. Walkways in the city centre are mostly specified. In some cases walkways are open or enclosed. In some areas, measures are taken to prevent un-authorised parking interference. Here, concrete blocks are erected to discourage car parking

Normally walking take place at ground level where, in the case of city centre, most of buildings along the streets are multi-storey. The functions of most buildings at the ground level are commercial activities which require convenient and prompt accessibility. The pedestrians are predominantly among the target population who can easily gain visual or physical access to the services offered in the buildings at ground level. Furthermore, some petty trading activities take place at some points along the walking routes, in defiance to the city planning conditions, and thus reducing the walking space although they claim to leave sufficient space for pedestrian to move (see Figure 12). Routes which attract higher population of pedestrian are mainly targeted and occupied by petty traders as the source of customers to their trading activities (See Figure 12). The most populated areas are predominantly close to the public function such as market places, transport stations or recreational areas which attract more walking people. 95 percent of 50 petty traders interviewed claim to choose their location based on abundance of pedestrian movements. 45 percent of them choose to be close to the bus stop to capture pedestrian moving away or towards the bus stop. 

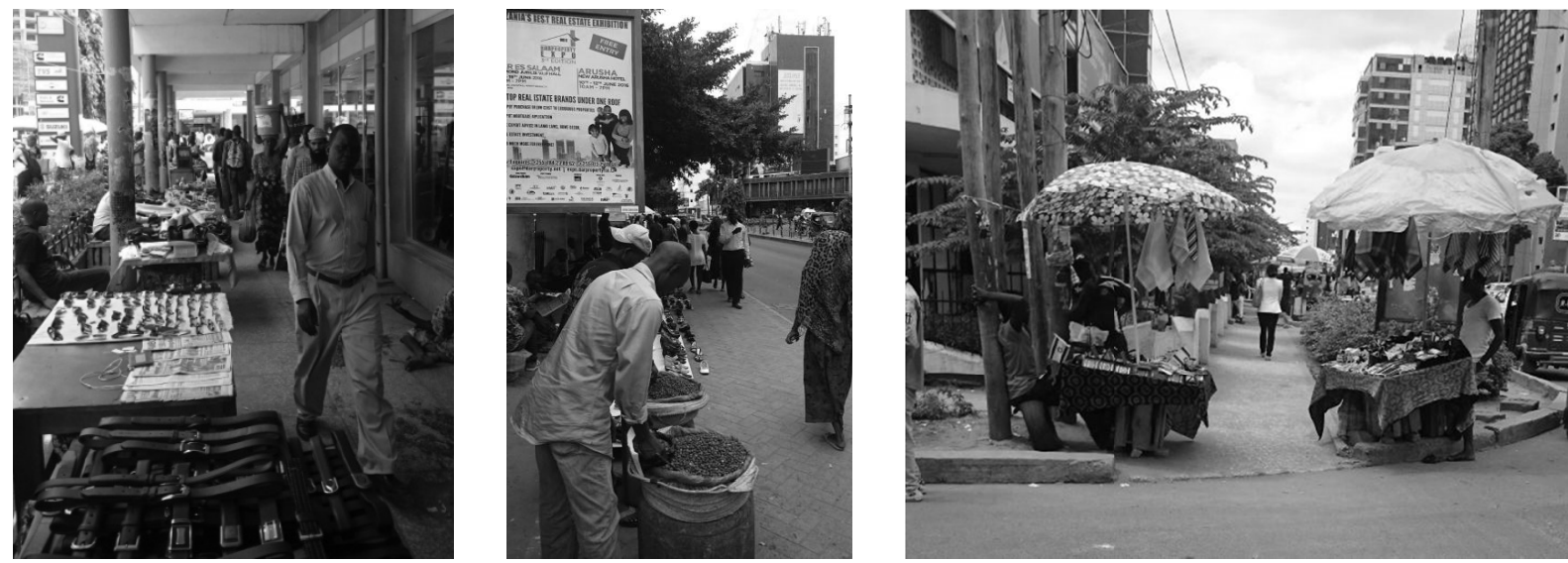

Figure 12. Unauthorised petty trading in city centre's walkways where petty traders claim to leave sufficient space for pedestrians to pass. Being attracted by the flow of walking people, they contribute a part of activities

which associate walking. The trading activities shown above are close to the major bus stop which attracts abundant pedestrians movements

In the city centre, the challenges faced in the walkways such as inconsistent paved surfaces, pot holes, inconsistent walkway space, intrusions by parked cars or occupation by petty traders were claimed by 50 percent of 120 walkers interviewed to affect their walking convenience and safety (see Table 1). In some cases walkway are obstructed by the building owners for security purpose or blocked by contractors for the construction activity (See Figure 6). However, 48 percent of interviewed pedestrians felt safe particularly due to the existing separation between car carriageway and pedestrian walkways. According to them, the intrusion of parked cars and petty trading activities along the walkway are not a big deal since they left some room for pedestrians to pass. Such pedestrians' opinion indicates the relatively recognition and understanding of the walking environment enough to take necessary precautions to handle the walking situations encountered. This also reveals that the walker tends to closely explore the walking environment and adopt the relevant walking behaviour.
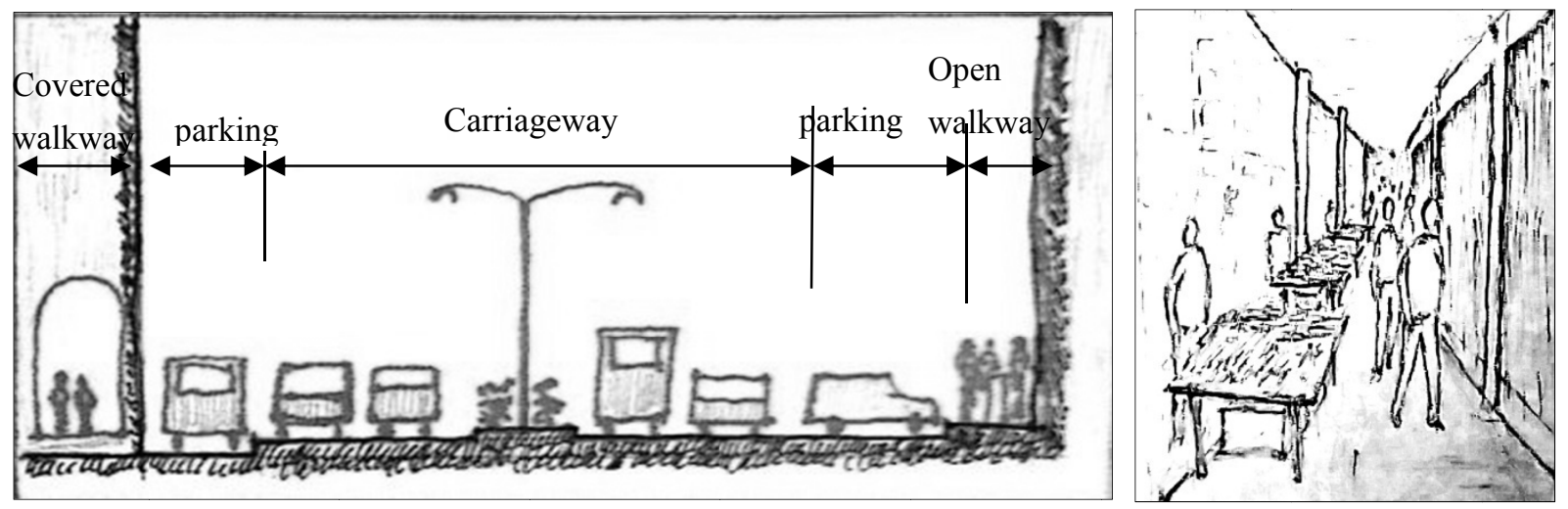

Fig. 13. In city centre: LEFT. car carriageway, parking and walkways are specifically provided. RIGHT, Petty trading get in and form part of walking activity especially in the highly populated areas

Walking experience appears to be contributed by the condition of walking environment and the visual field along the walking route which differ between the city centre and Sinza. While 32 percent of 120 pedestrians interviewed in city centre indicated that they enjoyed the walking experience including the view, the buildings and the street condition, only 25 percent of pedestrian in Sinza enjoyed the walking experience. Contrary to Sinza streets, walkways in the city centre are paved and separated from the carriageway, buildings are compact and tall which creates clear enclosure of streets enhancing the walking experience and the view. Such perspective indicates that walking activity apart from serving the mobility, social and recreational purpose; it can also be enhanced with sensory effect of environment bolstered by the relevant walking facilities and urban features such 
as effective landscape and attractive buildings.

\subsection{Pedestrians Encounters in Prevailing Walking Conditions}

From the more understanding acquired about walking and the context in which it takes place, the perception of walking by designers should be reconsidered especially for developing world cities where resources for provision of conventional facilities for walking are scarce. Despite the deficiency of walking facilities, as observed in Dar es Salaam, the pedestrians have to walk as a part of inevitable urban practice. Given to the situation, the study shows that pedestrians adapt to the prevailing walking settings by consistently negotiating through informal encounters to meet the mobility, social and spatial requirements as noted by some analysts that walking strengthen our social relationship to urban places as well as assisting our understanding of urban social space and thus a social activity (Shortel, 2016; Wundelich, 2008).

The lack of strict traffic guides and restrictions in streets, especially in Sinza where the walking, riding and driving are not separated, is mostly making the pedestrians feel unsafe. Inversely, it can possibly lead pedestrians, riders and drivers to become extra vigilant to avoid confusion among their different roles in the shared movements. These negotiated movements among different modes of travelling reflect rudimentarily the concept of 'shared space' but also the existence of relationship among walking with other urban activities (Hamilton-Baillie, 2008, Methorst et al, 2007). In such state of space, users react to less formal and less planned environment striving to consistently confront the event of the moment among different modes of mobility and space use. This may suggest that commendable lessons can be acquired from the informal movement practices that 'non-design or less-design' is not necessarily 'lack of rational intention for future use'. The study in Sinza and City centre indicates the existence of interaction and awareness among actors in walking sphere where in some instances one group of actors depend on the other, for instance, the pedestrians being customers to petty traders and vice versa. The proper understanding of human and his interaction with environment as well as his cultural, social and economic association with space may lead to less strict professional design which facilitates efficient interaction among human and the immediate environment in space and time. Thinking along this perspective, useful lessons acquired from informal field practices could be adopted as relevant design and planning input to complement the conventional practices, in this case, the relevant walking environment.

The field study area in Sinza and the City centre are observed to attract more purposive walking as a major means of transport making shorter distance within the city. Yet the desire for preconceived design is demanded by actors, especially the pedestrians, who demand amicable relation of walking, riding, driving, parking, vending and positive sensory effect of the environment. This may respond to the claim that the achievement of 3-D's (Density, Diversity and Design) requirements in creation of built environment provide convenient condition for more people to make walking trips than using other modes of transport (Kärrholm et al, 2014; Reyer et al, 2014; Blaga, 2013; Mehta, 2008). Certain walking spaces as well as formal and informal activities developed in public space are among the results of spontaneous reactions to meet the local pragmatic 'design' requirements. The pedestrians, street petty traders, the shop owners and other actors along the street engaged in public activities created a variety of actors in public space along the street portraying the image of urban life and the walking as an integral part. These outcomes concur with Shortell (2016) who associates walking with living in city as well as the means to extend social realm beyond and between home and work.

The empirical findings reveal a paradox where, in City centre, the designed walkways separated from other activities are intruded with other informal activities which assume the relationship with the existing activity in the course of real life and, in Sinza, the un-designed walking system is informally mixed with other related activities. These shared spontaneous development of walking environment between the city centre and Sinza area reflects a certain association of walking with other urban functions. Such walking practice is opposed to normative urban professionals' propensity which over-emphasise walking as a homogeneous, specific and less complex 'social activity'. Most studies denote walking as 'social activity' and a 'sophisticated' connector of human and his environment (Shortell, 2016; Braga, 2013; Gehl, 2010; Wundelich, 2008). With informal activities along the walking routes, the element of employment opportunity, socialising, recreating and trading indicate an exclusive socialization within the walking territory. This implies that when urban activities are favourably connected around walking there is great chance of enhancing vitality and vibrancy of activities. In design situation where variety of activities in urban space are discouraged, as observed in the city centre of Dar es Salaam, the variety of informal activities such as petty trading take over to fill the gap. The survival of informal activities within walking spaces in city centre, despite their disruption to formal design, reflects their importance as supplementary activities to walking and city space use. This remains to be an important lesson to professionals that walking holds an exclusive multi-dimensional factor in urban design which should be spared its position sufficiently. The result may contribute to reduced greenhouse gas emission, car congestion, transport 
cost and improve the health of the people as well as the general quality of life. This remarkable share of walking as economical, social, environmental and health promoting factor make it an important feature in design and planning for the living environment of urban community.

However, in a situation of cities in developing world where emphasis is mostly put on facilitating motorised mode of mobility, the view of modes of movement as isolated entities should be reoriented towards a wider perception where 'shared space' for movements are possible. This holistic view of movement may enable the city designers, planners and decision makers to handle the issues of mobility and space use holistically and thus reducing the conflicts which primarily arise from solving mobility aspects and the other uses.

\section{Conclusion}

The empirical study of walking has revealed the different perception among the designers, pedestrians and other actors within the walking space. The separation of walking with other activities in city centre explains the designer's normative view of walking as distinctive, homogeneous, specific and independent urban activity. However, the pedestrian and petty traders' reactions towards walking space indicate the relationship of walking with trading, socializing and recreating both in city centre, where walking environment is designed, and in Sinza, where walking environment is not designed. The informal activities associated with walking appear to be entertained with the actors in the walking space such as the interdependence between the pedestrians and petty traders. Further, the element of economic and employment opportunity to the petty traders appear to form inherent association of walking space in addressing the socio-economic condition of city inhabitants. The resulting association of walking with multifaceted activities make it a key factor facilitating vibrancy and vitality of urban functions. In this respect, the emerging informal activities associated with walking provide insight to urban professionals on the need for innovative and relevant solutions for walking space with harmonised multifaceted elements especially for developing world cities where walking facilities are rarely realised. Thus, urban design professional inclination and policy orientation for design of walking in cities of developing world should regard it as integral component of urban public space and the extended perspective of socio-economic context.

\section{References}

Anciaes, P., Nascimento, J., \& Silva, S. (2015). Mapping Pedestrian Accessibility and the Quality of Walking in an African City: Praia, Cape Verde. Energy, Climate and Air Quality Challenges: The Role of Urban Transport Policies in Developing Countries, 2-5 February 2015, Istanbul, Turkey. Turkey: CODATU.

Banyikwa, W. F. (2007). The Built Environment Motorisation and Road Traffic Safety in Tanzania: Outline of an Aletenative Explanation. The Journal of Building and Land Development, 14(1), 23-35.

Blaga, O.-E. (2013). Pedestrian Zones as Important Urban strategies in Developing the Community; Case Study, Alba Iulia Borough Park. Transylvanian Review of Administrative Sciences, 5-22.

Cox, W. (2012). Developing Africa: Toward Customer Oriented Urban Transport Policy. Paper presented to CODATU XV Congress, African Union Headquarters, 23 October 2012. Addis Ababa: Demographia,

Cubukcu, E. (2013). Walking for Sustainable Living. ASEAN Conference on Environment-Behaviour Studies, Hanoi Architectural University, Hanoi, Vietnam, 19-22 March 2013: "Cultural Sustainability in the Built and Natural Environment (pp. 33 - 42). Hanoi: Procedia - Social and Behavioral Sciences. https://doi.org/10.1016/j.sbspro.2013.08.335

De-Certeau, M. (1984). Walking in the City. In M. De-Certeau (Eds.), The Practice of Everyday Life (pp. 91 130). Califonia: University of California Press.

Gehl, J. (2010). Cities for People. London: Island Press.

Hamilton-Baillie, B. (2008). Shared Space: Reconciling People, Places and Traffic. Built Environment, 34(2), 161-181. https://doi.org/10.2148/benv.34.2.161

Jacobs, J. (1961). The Uses of Sidewalks: Safety. In R. LeGates, \& F. Stout (Eds.), The City Reader (4th ed., pp. 98-102). New York: Routledge.

Kärrholm, M., Johansson, M., Lindelöw, D., \& Ferreira, I. A. (2014). Interseriality and Different Sorts of Walking: Suggestions. The online platform for Taylor \& Francis Group content .

Kiunsi, R. (2013). A Review of Traffic Congestion in Dar es Salaam City from the Physical Planning Perspective. Journal of Sustainable Development, 6(2), 94-103. https://doi.org/10.5539/jsd.v6n2p94 
Leather, J., Fabian, H., Gota, S., \& Mejia, A. (2011). Walkability and Pedestrian Facilities in Asian Cities: State and Issues. Manila: Asian Development Bank.

Lekule, C. (2004). Place Dynamics: Meaning of Urban Spaces to Residents in Keko Magurumbasi Informal Settlement, Dar es Salaam, Tanzania. Copenhagen: PhD Thesis, Royal Academy of Fine Art.

Makki, S., Surat, M., Che-Ani, A., Farkisch, H., \& Mokhtarian, H. (2012). The Importance of Design Characteristics in Walking from Student's Perspective: A Case Study in Universiti Kebangsaan Malaysia. Journal of Building Performance, 3(1), 42-49.

Mehta, V. (2008). Walkable Streets: Pedestrian Behavior, Perceptions and Attitudes. Journal of Urbanism: International Research on Placemaking and Urban, 1(3), 217-245. https://doi.org/10.1080/17549170802529480

Methorst, R., Gerlach, J., Boenke, D., \& Leven, J. (2007). Shared Space: Safe or Dangerous? A contribution to objectification of a popular design. Shared Space at the WALK21 conference, 1 - 3 October 2007, Toronto. Toronto: WALK21.

Mkalawa, C. C., \& Haixiao, P. (2014). Dar es Salaam City Temporal Growth and its Influence on Transportation. Urban, Planning and Transport Research, 2(1), 423-446. https://doi.org/10.1080/21650020.2014.978951

Mrema, L. (2013). Creation and Control of Public Open Spaces: Case of Msasani Makangira Informal Settlement, Tanzania. Online Journal of Social Sciences Research, 2(7), 200-213.

Pendakur, S. (2005). Non-Motorized Transport in African Cities: Lessons from Experience in Kenya and Tanzania. The Sub-Saharan Africa Transport Policy Program (SSATP).

Planning Institute Australia. (2003). Planning Healthy Communities: A PIA discussion paper on public health and wellbeing: a basis for developing a draft policy statement on planning for health. Victoria: Planning Institute Australia.

Reyer, M., Fina, S., Siedentop, S., \& Schlicht, W. (2014). Walkability is Only Part of the Story: Walking for Transportation in Stuttgart, Germany. International Journal of Environmental Research and Public Health, 11(6). https://doi.org/10.3390/ijerph110605849

Shortell, T. (2016). Walking as Urban Practice and Research Method. In E. Brown, \& T. Shortell (Eds.), Walking in Cities: Quotidian Mobility as Urban Theory, Method and Practioce (pp. 1-16). Philadephia: Temple University Press.

Transport for London. (2004).Making London a Walkable City-The Walking Plan for London. London: Mayor of London.

Tribby, C., Miller, H., Brown, B., Werner, C., \& Smith, K. (2016). Assessing Built Environment Walkability Using Activity-Space Summary Measures. The Journal of Transport and Land Use, 9(1), 187-207.

WHO. (2011). Make Walking Safe: A brief overview of pedestrian safety around the world.Retrieved December, 2016, from http://who.int/violence_injury_prevention/publications/road_traffic/make_walking_safe.pdf

Wundelich, F. M. (2008). Walking and Rhythmicity: Sensing Urban Space. Journal of Urban Design, 13(1), 125-139. https://doi.org/10.1080/13574800701803472

\section{Copyrights}

Copyright for this articleis retained by the author(s), with first publication rights granted to the journal.

This is an open-access article distributed under the terms and conditions of the CreativeCommons Attribution license (http://creativecommons.org/licenses/by/4.0/). 